\title{
DIGITAL HISTORIC URBAN LANDSCAPE METHODOLOGY FOR HERITAGE IMPACT ASSESSMENT OF SINGAPORE
}

\author{
J. Widodo ${ }^{\text {a }}$, Y.C. Wong ${ }^{b}$, F. Ismail $^{\mathrm{c}}{ }^{*}$ \\ * Department of Architecture, School of Design \& Environment, National University of Singapore \\ 4 Architecture Drive, S117566, Singapore \\ a jwidodo@nus.edu.sg ${ }^{b}$ akiwyc@nus.edu.sg ${ }^{\mathrm{c}}$ fauzy@u.nus.edu
}

Commision II

KEY WORDS: Historic Urban Landscape, Heritage Impact Assessment, Reusable Big Data, Tangible \& Intangible, Architecture \& Urban Heritage Inventory

\begin{abstract}
:
Using the case study of Singapore's existing heritage websites, this research will probe the circumstances of the emerging technology and practice of consuming heritage architecture on a digital platform. Despite the diverse objectives, technology is assumed to help deliver greater interpretation through the use of new and high technology emphasising experience and provide visual fidelity. However, the success is limited as technology is insufficient to provide the past from multiple perspectives. Currently, existing projects provide linear narratives developed through a top-down approach that assumes the end-users as an individual entity and limits heritage as a consumable product.
\end{abstract}

Through this research, we hope to uncover for better experience of digital heritage architecture where interpretation is an evolving 'process' that is participatory and contributory that allows public participation, together with effective presentation, cultural learning and embodiment, to enhance the end-users' interpretation of digital heritage architecture.

Additionally, this research seeks to establish an inventory in the form of a digital platform that adopts the Historic Urban Landscape (HUL) into the Singapore context to better and deepen the understandings of the public towards architectural as well as cultural heritage through an intercultural and intergenerational dialogue. Through HUL, this research hopes that it will better shape conservation strategies and urban planning.

\section{INTRODUCTION}

The practice and discipline of urban heritage conservation in Singapore have notably progressed over the last decades as planners and policy-makers strive to deal effectively with new obstacles. These obstacles, such as the extent of the momentum of development resulting in the rapid growth of Singapore economy, have resulted in historic areas becoming the centres of economic expansion. The urban heritage areas have to take on additional new role as the social and cultural life causing new pressures to historic districts. The urban heritage would have to adapt to the changes through conservation, adaptive reuse or complete demolition.

United Nations Educational, Scientific and Cultural Organization (UNESCO) have recommended the HUL as a tool to integrate practices and policies of conservation and urban planning into the wider goals of urban development with consideration of the inherited traditions and values of different cultures. The HUL approach supports communities in their quest for adaptation and development while retaining the values and attributes linked to their history, collective memory and environment.

One of the HUL tools is "to reach consensus using participatory planning" (UNESCO HUL Methodology, 2011). Through civic engagement, it will facilitate "intercultural dialogue by learning from communities about their histories, traditions, values, needs and aspirations" (ibid). Such civic engagement tools could come in the form of information and communication technology, such as a digital platform to understand, document and present the elaborate layers of urban areas and their integral sections. This tool would be useful to assist in a holistic conservation that goes beyond the form and structure of heritage architecture and integrate the phenomenology of the architecture. Heritage architecture could be seen as a form of conservation of the last resort if demolition is the only option.

\section{UNESCO HISTORIC URBAN LANDSCAPE}

UNESCO's (2003) charter on the "Preservation of Digital Heritage" which defines "Digital Heritage" as intangible heritage that is born digitally or acts as a digital surrogate, and its primary role is to protect the loss of tangible and intangible data on the digital platform or within the technological domain and its features includes weaving, conservation, facilitating, representation, reproduction digital reprocessing (Roussou, 2002) and actualizing heritage architecture (both tangible and intangible contents) digitally using the advancement of virtual reality technologies and simulate it using graphics technology (Reffat, Nodal, 2013). However, there are scenarios where the built physical heritage architecture exists simultaneously with the digital heritage, and it produces a new realm, which the digital and physical subsist and interact (Siltanen, 2012).

The rise in popularity of heritage architecture on the digital platform and the increasing value of the digital resources prompted UNESCO to adopt the charter. By adopting the 
charter, UNESCO is acknowledging heritage architecture on the digital platform as a legitimate space. Therefore, it becomes necessary for the digital platform on heritage architecture to effectively communicate, learn, store and manage to increase the end-users' awareness and empathy on heritage architecture over time and space. However, there are instances where intangible data are lost in the preservation of digital heritage (tangible data).

Consequently, UNESCO came up with recommendations as a tool to integrate practices and policies of conservation and urban planning into the wider goals of urban development with consideration of the inherited traditions and values of different cultures. This tool is a "soft law", and Member States can implement it on a voluntary basis as HUL is a series of methodologies that will be used for heritage impact assessment (HIA) for the country.

The recommendations are modified to suit the context of the city on which the Member States intend to implement. These recommendations and tools are also used for urban planning and conservation strategies. In this project, the final digital outcome (initially a website) is to allow for analytical frameworks and processes of HIA that will affect the shape of urban planning and conservation strategies in Singapore. In the creation of the website, various data sources of tangible and intangible origins will be collected to populate the data in the website. The HUL approach could impact on the future socio-economic development by capitalising on its tangible and intangible urban heritage through comprehensive mapping of Singapore which translates into the cultural heritage of Singapore and thus, increasing a sense of belonging and rootedness. This could enhance the overall cultural image of Singapore.

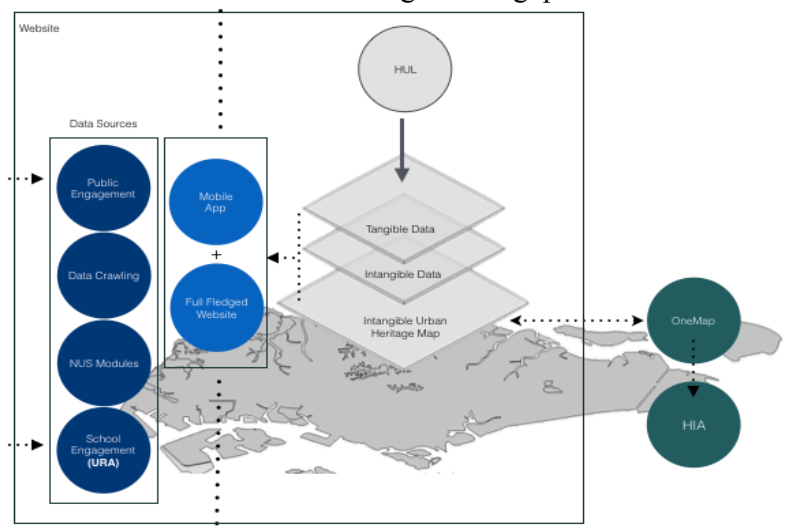

Figure 1. Revised Methodology of HUL for Singapore's HIA

\section{SCHOOL ENGAGEMENT}

The review of "school engagement" is an example provided in the paper on framework of community engagement in heritage; revealing some qualities of "participatory" as one of the paper's objective.

The school engagement aims at getting children interested in urban planning and urban design as a way of generating bottomup initiative and getting kids interested in design. The workshop done over the summer vacation helps to increase appreciation of urban development and heritage. It also helps them understand the concept of space and structure so that they could appreciate their built environment. When they care about their surroundings, they would want to take ownership of space back from the government. The programme is done through mapping of the area, making models, talking to the expert \& community leader, doing interviews and vision about their future space. It is done in group works and discussion, which will be presented to the class and city.

The appreciation and understanding of traditional built heritage have to be fostered since young. When they grow up, they would appreciate the built heritage and pass on this knowledge to their children to instils the values of protecting the heritage, tradition and history. This continuous cycle of passing down of knowledge will ensure that the traditional built heritage will remain alive and as relevant in the present as it was during their ancestor's time. It is also to protect the identity of the place so that it will not be easily altered by anyone in the future.

When community involvement reached out to the younger audience, such as school students to instil the values of protecting the heritage, tradition and history, and at the grassroots level, it helps to avoid the overemphasis on historic area but instead shift the focus of history and heritage on their immediate neighbourhood. This will enable us to protect the neighborhood identity through the understanding of the history of the neighborhood. If the neighbourhood community care for their neighborhood area, the concept of protecting our heritage, tradition and history could be easily done nationwide. The methodology of the school programme is encapsulated below.

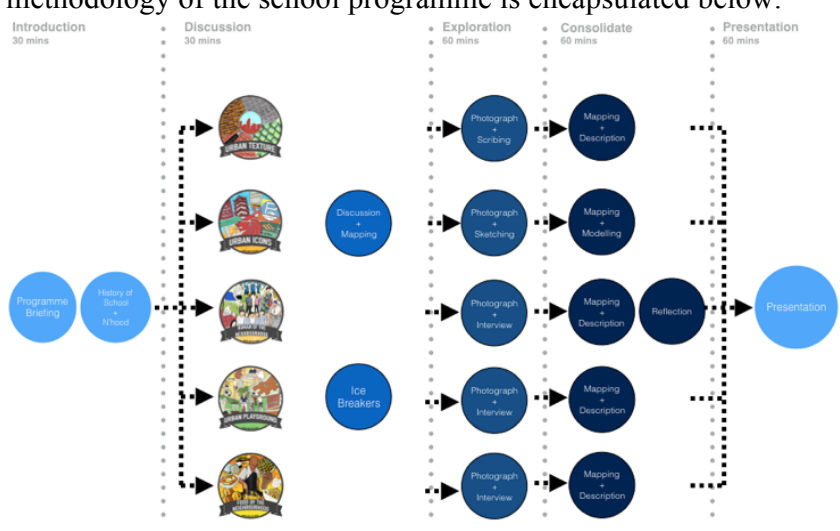

Figure 2. School Engagement Methodology

\section{VARIOUS THEORETICAL MODEL ON INTERPRETATION OF HERITAGE ARCHITECTURE ON A DIGITAL PLATFORM}

In this section, it will focus on the various existing theoretical models (i) Copeland's Information Flow of Approaches (ii) Langer's Model for Mindful Interpretation and (iii) Heritage Butterfly Model. The first two models expound on the presentation, interpretation and communication of heritage in the digital platform, while the third model discusses on the assessment of heritage architecture on a digital heritage platform.

\subsection{Theoretical Model A: Copeland's (2006) Information Flow of Approaches}

In this model, it outlines both the positivistic information flow approach and constructivist's information flow approach. The positivistic information flow approach, seen in many of the existing heritage platform, recognises only information which are being scientifically verified or is capable of logical proof. Such approach usually emphasizes on the locational and factual knowledge of heritage and is didactic. The audience to the site is also solely viewed as consumers of knowledge. However, the other approach, the constructivist's information flow of approach, focuses on constructing understanding and 
interpretation of heritage information, through reflection in the midst of interaction within the website. This approach serves to emphasize on concepts of historical changes and understanding. Unlike the positivistic information flow approach, audiences to the site are treated as thinkers with present conceptions and emerging ideas about the past. The public's exploration is highly valued, and interpretation strategies are aimed to encourage discourse. Its assessment and evaluation seek to discover audience perspectives to improve interpretation.

Thus, it will be effective for a digital platform, which seeks participation from all sectors of society, to adopt the constructivist's information flow approach. This approach allows for the facilitation of intercultural dialogue with regards to their histories, traditions, values, needs and aspirations. Furthermore, it helps documentation and understanding of the complex layering of urban areas and their integral components (UNESCO HUL Methodology, 2011) by accommodating for interpretation from varied perspectives.

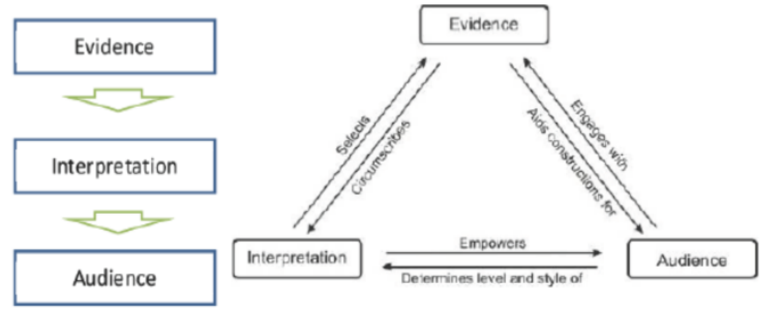

Figure 3. Copeland's Information Flow of Approaches

\subsection{Theoretical Model B: Langer's Model for Mindful Interpretation}

In the second model, it reviews how the quality and quantity of contributions in heritage on the digital heritage platform, as well as the learning and understanding on the digital platform, are dependent on the cognitive state of the audience (Langer, 1989).

According to Langer (1989), the Mindfulness cognitive state occurs when an interface provides novelty, conflict or unfamiliarity that does not follow a script that is didactic, typically found in the constructivist's information flow approach. Mindlessness, on the other hand, occurs when an interface is repetitive, irrelevant and unimportant. This results in the audience to behave in a way that follows a cue from a script, typical of the positivistic information flow approach.

Thereby, it will be effective for the digital platform to have an interface that facilitates the mindful cognitive state. This will in turn bring about high levels of learning, satisfaction as well as understanding. Moreover, this cognitive state promotes mindful contributions further refining the interpretation of digital heritage as presented on the site and as a result strengthening the constructivist information flow approach. On the other hand, the mindless cognitive state brings about otherwise and hence not facilitating mindful contributions to be made to the digital platform, weakening the constructivist information flow approach and possibly altered into one that is positivistic instead.

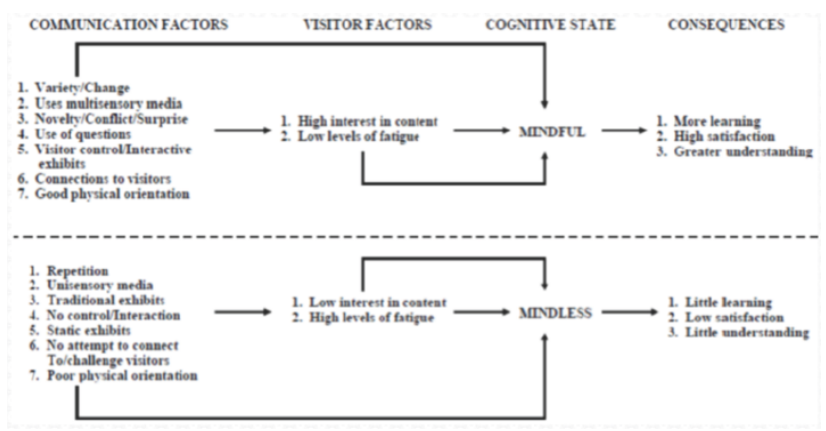

Figure 4. Langer's Model for Mindful Interpretation

\subsection{Theoretical Model C: Heritage Butterfly Model}

mAAN (modern Asian Architecture Network) created a standardised evaluation of the urban cultural heritage and property through a heritage butterfly model. It serves to advocate a balance between the official and public rhetoric. The left wing represents the value of the ordinary people, and the right wing represents that of the experts. In addition to that, time-related value (the past, present $\&$ future) is also considered. The heritage is evaluated using six factors. The implementation of such a model serves to create greater public awareness among the people of some significant heritage architecture around the city and encourage experts to think of efforts to treat the environment which is historically significant to the public.

The "heritage butterfly" illustrates the sets of evaluation based on Table 1 and Figure 5, while Figure 6 shows the various evaluation outcomes. The butterfly model quantifies the public and expert's opinions by aiming for a heritage butterfly whose wings are of similar shape and size, which means that the heritage architecture is important to both experts and public. 'Experts' refer to both government officials and heritage academics. If the expert right wing is small, it suggests that the experts should be more involved in the heritage architecture to raise the value of the built heritage architecture or there might be a reason why the experts do not value the heritage architecture. If the public left wing is small, the expert should take the effort to make the public aware of the building's value. Additionally, the butterfly model could also provide for the equal distribution of both the tangible heritage architecture as well as the intangible heritage, working the same way as the above-mentioned.

This analysis thus serves as an indicator of how we should make the intervention should the size of the wings differs, which indicates uneven resources are being put to specific heritage architecture. The model is simplified to a level which allows everyone to understand. Subsequently, it could also be employed on an international level.

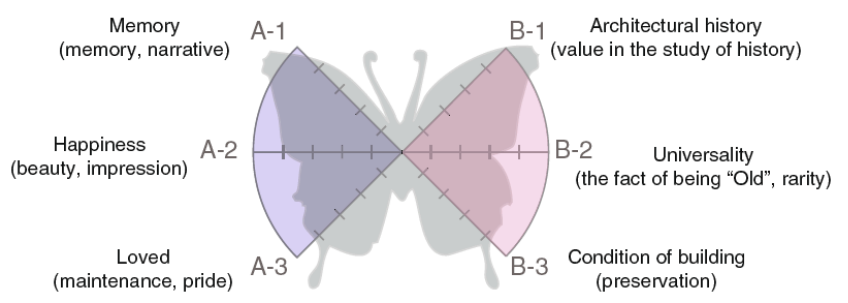

Figure 5. The 6 factors imagined in a butterfly diagram (Muramatsu et all, 2009) 


\section{CASE STUDY OF EXISTING HERITAGE WEBSITES IN SINGAPORE}

The research surveyed some digital platforms that document heritage architecture, from both the government and public enthusiasts, to draw insights on how they adopt the constructivist information flow approach and facilitate the Mindful cognitive state. The survey revealed the shortcomings of the various digital platforms. The research surveyed some digital platforms that document of heritage architecture, from both the government and public enthusiasts, to draw insights on how they illustrate several of the criteria ascribed in the above models.

\begin{tabular}{|c|c|c|c|}
\hline \multicolumn{4}{|c|}{ Standards for Evaluation of the Urban Cultural Heritage and Property } \\
\hline \multirow{2}{*}{\multicolumn{2}{|c|}{ Standards for Evalua }} & A (Public) & B (Experts) \\
\hline & & $\begin{array}{l}\text { The large number of } \\
\text { people except experts }\end{array}$ & Experts \\
\hline $\begin{array}{l}1 \\
\text { Past }\end{array}$ & $\begin{array}{l}\text { Value in } \\
\text { terms of } \\
\text { Memory }\end{array}$ & $\begin{array}{l}\text { Memory of those } \\
\text { who exist there } \\
\text { Memory of the } \\
\text { humanity }\end{array}$ & $\begin{array}{l}\text { Value in the } \\
\text { study of history }\end{array}$ \\
\hline $\begin{array}{l}\text { Future } \\
\end{array}$ & $\begin{array}{l}\text { Value in } \\
\text { terms of } \\
\text { Future } \\
\text { Happiness }\end{array}$ & $\begin{array}{l}\text { Possibility for the } \\
\text { establishment of } \\
\text { value in the future } \\
\text { Generating } \\
\text { happiness for the } \\
\text { humanity }\end{array}$ & $\begin{array}{ll} & \text { Proper condition } \\
\text { of preservation } \\
\text { - } & \text { Possibility for } \\
\text { revitalization }\end{array}$ \\
\hline $\begin{array}{l}3 \\
\text { Object }\end{array}$ & $\begin{array}{l}\text { Value in } \\
\text { terms of } \\
\text { the Object }\end{array}$ & 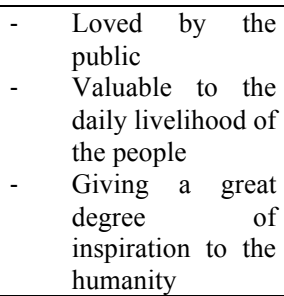 & $\begin{array}{ll}\text { - } & \text { The fact of being } \\
\text { "Old" } \\
\text { - } \\
\text { - } \text { Rarity } \\
\text { Evidence of the } \\
\text { regional } \\
\text { characteristics } \\
\text { - Giving } \\
\text { inspiration to } \\
\text { experts }\end{array}$ \\
\hline
\end{tabular}

Table 1. The six factors to evaluate heritage architecture (Muramatsu et all. 2007)

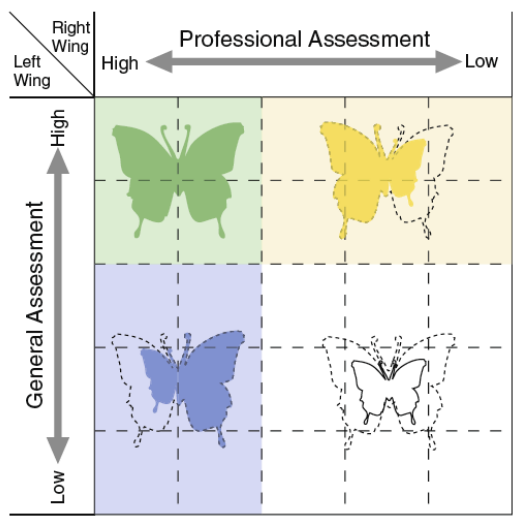

Figure 6. Analysis of built heritage architecture using the "Heritage Butterfly" model (Muramatsu et all. 2009)

\subsection{Case Study A: State of Building}

State of Buildings (SOB) appears to employ the constructivist information flow model. It relies on SOB contributors as well as the contributions of active users to construct understandings and interpretations of Singapore's Urban Heritage based on existing evidence. Additionally, these contributions are anchored to existing sites or buildings that are usually presented with concepts such as chronological changes to the site, evidence and interpretations emphasised. The audience of the site is supposedly viewed as thinkers whose exploration, assessments and contributions are highly valued.
In regard to the type of interface, whether supporting the mindfulness cognitive state or the mindless cognitive state, some SOB features an attractive user interface with a consistent colour theme and fonts to retain audience attention.

In aiding audience exploration and discovery, contributions are compiled into Places, Neighbourhoods, Trails, Lists and Stories linking relevant contributions together. These categories are also accompanied with all the other contributions to encourage discovery of the site's or building's relationship with others. In terms of the information flow approach, heritage information as presented on SOB, appears to be didactic. This could be a result of various factors that have caused the interpretation of heritage information on SOB to be predominantly shaped by its contributors as opposed to being equally shaped with active participants through their contributions. Conceivably, due to several communication factors.

Firstly, the SOB interface lacks the ability for user control and interaction. For example, maps that accompany contributions while are informative in delineating the location the sites or buildings, are static, non-interactive and do not display and link other relevant or related sites or buildings in the vicinity. This results in the contribution to be viewed by the audience without the context of other relevant or related sites or buildings. Additionally, contributions do not take advantage of multisensory media, only using pictures to illustrate concepts such as chronological changes to the site or building. These communicational factors regrettably miss out on the opportunity to encourage audience exploration, mindful conception for discourse and further contribution.

Secondly, the SOB interface does not encourage dialogic interaction. Basic features that could encourage dialogic interactions amongst users such as a "comments section" to reveal the reactions and comments of the contribution are not present. Additionally, active participants are unable to interact with SOB contributors to shape the interpretation of heritage information presented on the website. Contributions that are made by active participants, unfortunately, do not build upon SOB contributions.

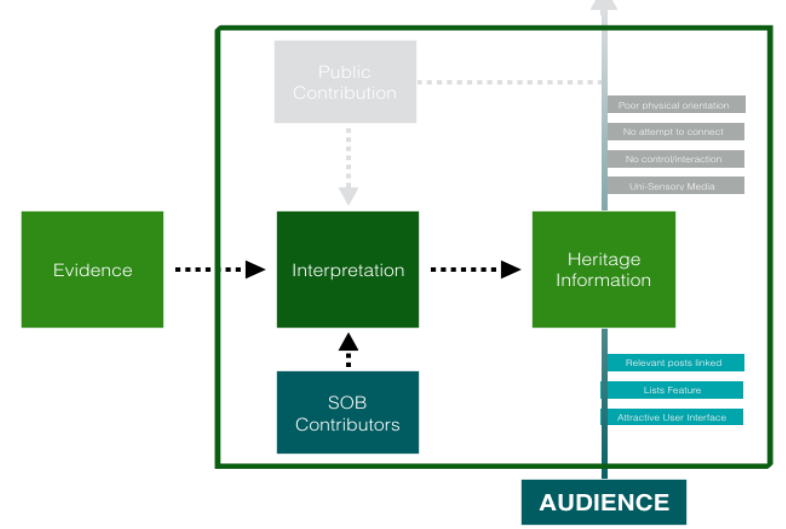

Figure 7. State of Building Information Flow Analysis

The culmination of these communication factors might have unfortunately resulted in low levels of interest in the content and thus little motivation for the audience to make mindful contributions to shaping the interpretation of heritage information presented on the website. Additionally, the constructivist information flow model, originally intended for the website, when coupled with sparse and non-meaningful user contributions has altered it to be one that is positivistic. 


\subsection{Case Study B: Singapura Stories}

Singapura Stories likewise appears to employ the constructivist information flow model. It relies on Singapura Stories contributors, collaborators as well as the contributions of active users to construct understandings and interpretations of Singapore's Urban Heritage. Additionally, these contributions are anchored to existing sites or buildings that are usually presented with concepts such as chronological changes to the site, evidence and interpretations emphasised. The audience of the site is supposedly viewed as thinkers whose exploration, assessments and contributions are highly valued.

In regards to the type of interface, whether supporting the mindfulness cognitive state or the mindless cognitive state, some Singapura Stories contributions make use of multi-sensory media such as photos and maps. These maps animate to identify chronological changes to a particular building or site. Additionally, Singapura Stories contributors and collaborators often provide in-depth analysis of chronological changes as well as interpretations of Singapore's Urban Landscape. These features help the retain audience interest in the content and help to construct mindful interpretations.

In respect of audience exploration and discovery, contributions in Roots are accessed by the audience are not linked to others that are relevant or related. This results in the contribution to be viewed by the audience without the context of other relevant or related sites or buildings. In terms of the information flow approach, as with SOB, heritage information presented on Singapura Stories appears also to be didactic. This is possibly a result of heritage information predominantly shaped by Singapura Stories contributors as opposed to being equally shaped with active participants through their contributions. Conceivably due to several communication factors.

Firstly, the Singapore Stories' again lacks the ability for user control and interaction. For example, the aforementioned animated maps, while informative in identifying chronological changes to a particular building or site, are static and noninteractive. These communicational factors again, regrettably miss out on the opportunity to encourage audience exploration, mindful conception for discourse and further contribution.

Secondly, Singapura Stories' interface attempts to encourage dialogic interaction with features such as the "comments section" to reveal the reactions and comments of the contribution. These sections, however, are usually empty. Moreover, comments that are left in this section are usually not replied by Singapore Stories' administrators or contributors. Additionally, like SOB, active participants do make contributions are unable to interact with Singapura Stories contributors to shape the interpretation of heritage information presented on the website.

The culmination of these communication factors might have, unfortunately, resulted in low levels of interest in the content and thus little motivation for the audience to make mindful contributions to shaping interpretation of heritage information presented on the website. As was with SOB, the constructivist information flow model that was originally intended for the website, when coupled with sparse and non-meaningful user contributions has unfortunately altered it to be one that is positivistic.

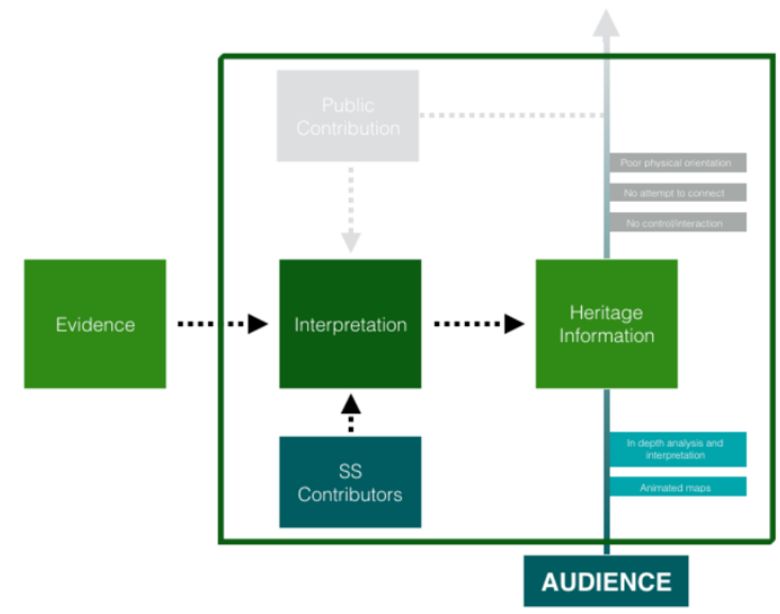

Figure 8. Singapura Stories Information Flow Analysis

\subsection{Case Study C: Roots}

Roots, unlike SOB and Singapura Stories, employs the positivistic information flow model. It relies solely on the National Heritage Board's (NHB) contributors to construct understandings and interpretation of Singapore's Urban Heritage. Posts are presented with emphasis on locational and factual knowledge. The audience of the site are viewed solely as consumers of knowledge and as such heritage information presented is didactic.

With regards to the type of interface, whether supporting the mindfulness cognitive state or the mindless cognitive state, Roots, similar to SOB, features an attractive user interface, with a consistent colour theme and fonts to keep audience attention to the site. Its posts make use of multi-sensory media such as highquality photos and videos to enhance content and retain interest. Additionally, Roots integrates mediate social features to give the audience the ability to share and react to these posts on popular social media sites such as Facebook and Twitter.

In aiding audience exploration and discovery, posts accessed by the audience, similar to SOB, are accompanied and linked to other relevant posts. These posts are also occasionally integrated with trail maps that help to reveal the links between buildings or sites.

There are several shortcomings in Roots as follows. Roots does not feature a clear central user interface. It features various sections, Read Stories, Visit Museums, Visit Monuments, Read Publications, Explore National Collection, each of which features its own interface. This has unfortunately resulted in an experience that is convoluted for the audience.

Most posts on Roots also lack the ability for user control and interaction, similar to the previous 2 case studies. Maps that delineate the sites or buildings that could encourage user exploration and the discovering of the context and relationships between sites or buildings do not accompany most posts. These interactive maps are instead the main interface used for the "Trails" and "Places" section. While these maps are integrated into some posts, most posts that audience does visit are mostly seen as individual sites or buildings not understood in context to its surroundings.

While as stated previously, social media integration of Roots gives the audience the ability to share are react to posts, it does 
not attempt to interact its audience in a dialogical manner to shape its interpretation of heritage information presented on the website. Posts are not accompanied by "comments section", there is no ability for active participants to contribute their perspectives.

The lack of dialogic interaction between the audience and the NHB contributors and the lack of ability for the audience to contribute their perspectives to shape the interpretation of heritage information presented on the website is, however, typical of a positivistic information flow model that instead seeks for validation of its content from the audience. This model however coupled with aforementioned communication factors between the audience and the website interface, namely a convoluted user experience, the lack of interactive maps that accompany posts and a lack of dialogic interaction may result in low levels of interest in the content. This is despite an attractive user interface and the use of multi-sensory photos and video.

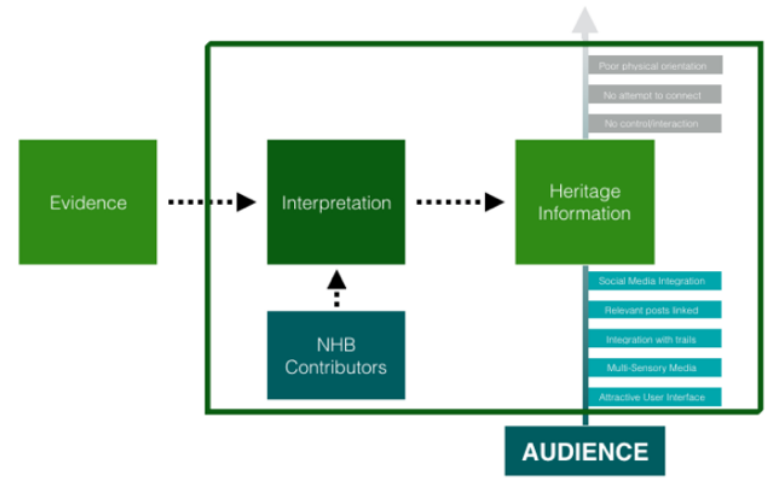

Figure 9. Roots Information Flow Analysis

\subsection{Case Study D: Singapore Memory Project (SMP)}

Singapore Memory Project employs the constructivist information flow approach. However, unlike SOB and Singapura Stories, it relies solely on contributions of active users to construct understandings and interpretation of Singapore's Heritage. These contributions are anchored to points on a map and are usually presented as narratives and memories of a particular site or building. The audience of the site is viewed as thinkers whose contributions and assessments are highly valued.

In regards to the type of interface, whether supporting the mindfulness cognitive state or the mindless cognitive state, most public contributions on Singapore Memory Project are largely written and largely make use of photos, with contributions made my NLB's Memory Makers making use of high-quality videos. These contributions are sorted into "collections" while outstanding contributions are highlighted.

In aiding audience exploration and discovery, all contributions are also sorted by chronology, location and time. Contributions sorted by location are geo-located on to a map and, relevant contributions are linked to each other.

There are several shortcomings in SMP as follows. Despite the large amount of public contributions to Singapore Memory Project, high quality and informative posts that are relevant to Singapore's Urban Heritage are hard to come by. This is possibly an outcome of the audience being in a Mindless cognitive state. This could be evidenced by the fact that while comments sections accompany all public contributions, they are mostly empty leading to the conclusion that contributions made by active participants might not be a result of a dialogic process between the audience. Secondly, contributions that are made to the platform are usually of low quality and low relevance to Singapore's Urban Heritage.

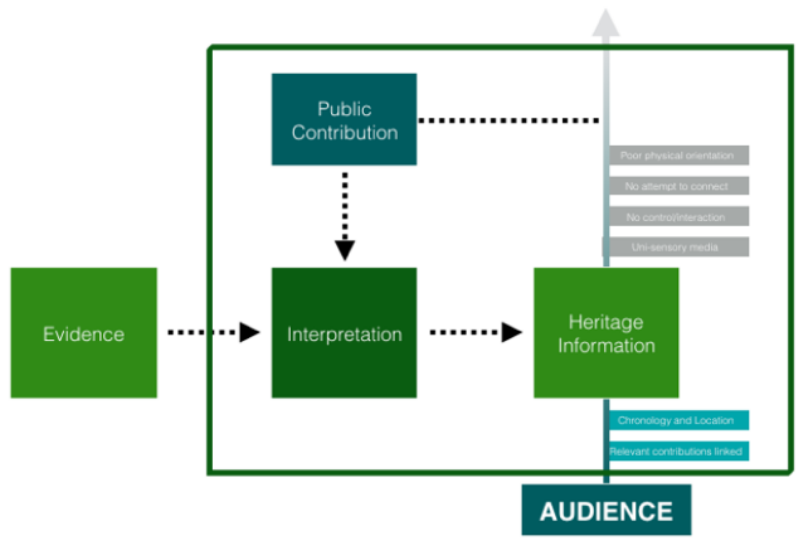

Figure 10. SMP Information Flow Analysis

\subsection{Overview of Website Comparisons}

Most of the websites surveyed employed the constructivist information flow approach, relying on a mix of contributions of active users and owners of the websites to construct understandings and interpretations of Singapore's Urban Heritage based existing evidence. Additionally, these contributions are anchored to existing sites or buildings that are usually presented with concepts such as chronological changes to the site, evidence and interpretations emphasized. The survey informed the gaps and linkages, which arise between the existing landscape of heritage architecture on a digital platform and published research that the proposed digital platform hopes to fill.

Generally, the four websites across do show simultaneously characteristics of Langer's mindful cognitive state and mindless cognitive state. Most of the sites surveyed lack the ability for user control and interaction. For example, maps that are display narratives of built heritage are often static and non-interactive. In encouraging audience exploration and user discovery, three out of four websites show attempts of it by linking various contributions and categories together.

\section{OBJECTIVES FOR A DIGITAL PLATFORM}

As a result, this research has developed the following objectives for an effective Digital Platform.

1. Develop holistic (tangible and intangible) building information for all buildings in Singapore (UNESCO HUL Methodology, 2012)

2. Facilitate high levels of interest from the audience (Langer's Model of Mindful Interpretation, 1989)

3. Accommodate for Mindful heritage professional contributions for "tangible and intangible" heritage information (Langer's Model of Mindful Interpretation, 1989 \& Copeland's Constructivist Information Flow Approach, 2006)

4. Accommodate for Mindful public contributions for "intangible" heritage information (Langer's Model of Mindful Interpretation, 1989 \& Copeland's Constructivist Information Flow Approach, 2006)

5. Facilitate dialogic interaction (amongst heritage professionals and active participants from the public) to develop and shape a holistic interpretation of Singapore Urban Heritage. (Rahaman, 2012) 


\section{FEATURES OF A DIGITAL PLATFORM}

\subsection{Effective Presentation}

- Easy orientation and navigation system (Langer, 1989)

- Central map interface

- Makes use of multi-sensory media (Langer, 1989)

- Photos \& video

- Changing maps with time

- Openness in adding or adopting new information

- User contribution

- Key events

- Happenings

- Connection to the visitors' past experiences

- Network

A mobile application should complement the website and dialogic interface such as Facebook. It does not necessarily be an application. It could be a website that is mobile-friendly. The purpose of the mobility is because there is a need for an openness to new information where the end-users could contribute ondemand. It also enables greater connection to the digital platform with the end-users.

Separation of the digital platform into three separate platforms (mobile/web/dialogic interaction website to facilitate discussion) ensures the effectiveness of presentation and efficiency of knowledge documentation, transmission and archiving. It creates a variety in content deliverance, creates a novelty for a surprise in content presentation and challenges the end-user to explore the interface as well as the content.

\subsection{Cultural Learning}

- Encourage audience to discover relationships and context of sites or buildings network

- Encourage audience to contribute meanings and values through sites or buildings

- Provoke audience to reveal symbolic meanings of sites or buildings

The website should act as the archive for the heritage architecture on a digital platform where it will enable greater cultural learning. The website will be collecting and storing the information on heritage architecture, and it will reveal more significant meanings on the heritage architecture should the endusers want a greater understanding of the heritage architecture. The website will facilitate discovery of new information for the end-users. There is also a greater variety of content on the website. This will enable the end-user to switch from Facebook to the website should they want to find out more about the heritage architecture.

\subsection{Embodiment}

- Promoting active participation, (through incentive or gamification)

- Encouraging task accomplishment

- Butterfly model

- Ensuring real-time feedback

- Comments section

\subsection{Dialogic Interaction}

- Maximising interaction, allow audience to explore, manipulate and contribute

- Central map interface

- Encouraging discourse

\author{
- Comments section \\ - Key events \\ - Promoting dialogue between audience, public and heritage \\ experts \\ - Comments section \\ - Key events
}

Instead of creating a digital platform that facilitates dialogic interaction on the platform (website or mobile application), it should be done on a third party website where the public endusers have already frequented such as Facebook. Many companies have facilitated their discussion to happen on Facebook such as Humans-of-New York (HONY) or SGAG (9GAG in Singapore). Facebook contains more than five hundred groups who are concerned with heritage, and a consolidation of those groups would be able to maximise interaction, encourage discourse and promote dialogue between the participants, locals and experts, as it will increase the number of participants. These spaces are akin to Oldenburg (1989) description of a third place as there are similar characteristics found between the virtual and physical worlds. The Facebook interface rest on the neutral ground, a leveller, there is only one main activity that is to discuss, accessible \& accommodating to the users, people frequent Facebook even though they might not visit the page and it is playful where it ensures that users have fun. Thus using already available platform such as Facebook will enable greater facilitation of discussion and dialogic interaction to ensure the sustainability. In addition to that, it embodied interaction as it promotes active discussion and participation on the narrative level. Real-time feedback is a given as everyone could comment on the issue.

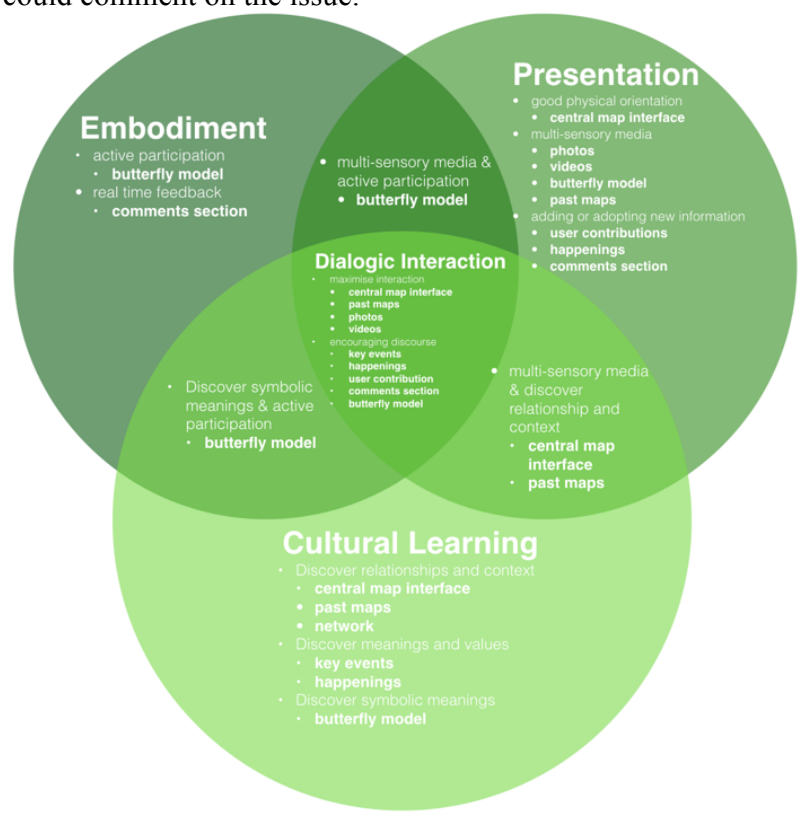

Figure 11. Classification of website features based on Rahaman (2012) recommendations.

\section{CONCLUSION}

The proposed digital platform could serve as a means of consolidation of existing digital platforms that usually duplicate each other in functions and purpose. Additionally, in taking advantage of the significant amount of data on Singapore's tangible architectural and cultural heritage that can be found in existing government databases, an architectural heritage (tangible heritage) layer on the proposed digital platform that serves as an anchor for other sources that pertain to architecture 
and cultural heritage (intangible heritage) of a particular building or site as well as public and professional contributions. This consolidation could also facilitate and maximise the shared economies model of knowledge, skills, and resources.

It is envisaged that the proposed digital platform with the adoption of HUL becomes a tool that holistically evaluates the value of a particular building or site to Singapore's urban heritage. This tool will then allow for critical frameworks and processes of HIA that affect the shape of conservation strategies and urban planning for lasting contributions to Singapore's heritage scene. Currently, in development, the proposed Digital Platform can be demonstrated in through the following link: https://youtu.be/seoZX5QikUw

The proposed digital platform integrates the social media and has a map based interface, which encourages exploration and interaction. It also links related buildings and places together to allow discovery of relationship. The websites adopts the butterfly model, placing an equal emphasis on experts and the ordinary people. Key events, photos and plans are arranged in a chronological timeline. This digital platform showcases 'happenings' in relation to the buildings and places, and focuses on the contribution of stories by the public.

There are several advantages of heritage architecture on a digital platform (El-Razaz, 2007). First, it enables us to document the tangible and intangible heritage architecture from any location. It could be in the form of a mobile phone application where the public could do documentation online by inserting intangible heritage while in public.

Secondly, it will enable the recovery of lost heritage architecture and recreate, reconstruct and reimagine it digitally. This is crucial in Singapore where they had demolished many heritage architectures or architecture of societal importance to make way for urbanisation. Urban Redevelopment Authority (Singapore's urban planning authority) had discussed this, but the need for such recreation is still ongoing since they are already lost and what significance of the recovery would do for the public.

Third, it will assist in the education process for students in tertiary education as well as general education schools (primary schools to junior college). It will give them a good sense of heritage and to be invested in their heritage. The details and the recreation of the heritage architecture will provide them with a good sense of spatial visualisation. Thus, they could get involved with the activities and increase the interaction with the heritage architecture to foster a greater learning experience.

Fourth, it will contribute to the tourist and those who are foreign to a particular heritage. It will help them to spread the heritage, culture and tradition beyond those who are native to the heritage. Presenting the past and the present of the heritage architecture will enable the visitors to imagine the heritage and tradition through augmented reality.

Lastly, it will help in creating an archive for the future generation, researchers who would like to study the heritage architecture and its landscape \& urban environment better and conservationist who would like to restore the heritage architecture. The heritage architecture on a digital platform will contain accurate data that will assist in physical or digital restoration.

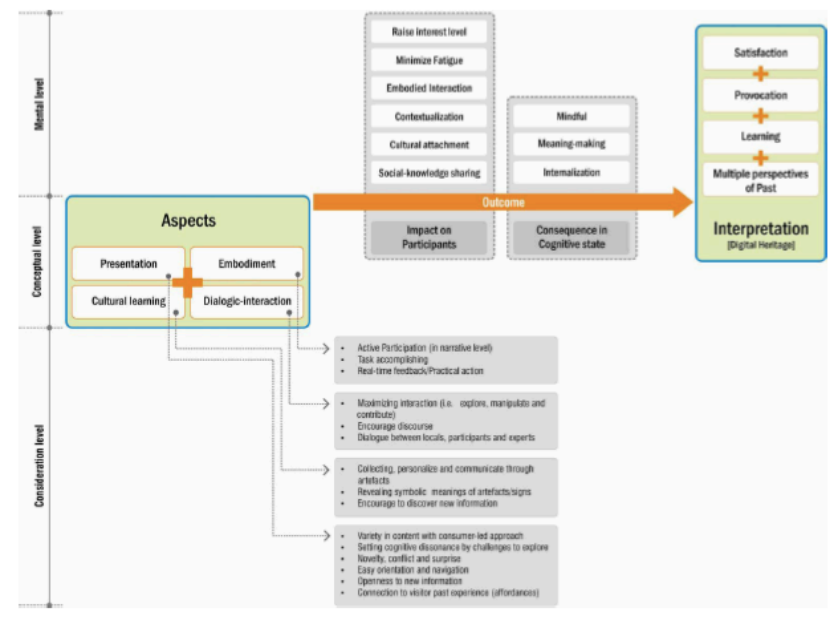

Figure 12. Framework for Interpreting Digital Heritage (Rahaman, 2012)

\section{ACKNOWLEDGMENTS}

We thank all the volunteers, and all publications support and staff, who wrote and provided helpful comments on previous versions of this document. The authors gratefully acknowledge the grant from Singapore's Ministry of Education Tier 1 Grant for the success of this research project. This research is also supported by the National Research Foundation, Prime Minister's Office, Singapore under its International Research Centers in Singapore Funding Initiative.

\section{REFERENCES}

1) Copeland, T., 2006. Constructing Pasts: Interpreting the Historic Environment in Hems, A. \& Blockley, M. R. (eds.) Heritage Interpretation. London, New York, Routledge.

2) El-Razaz, Z., 2007. Virtual Heritage in the Digital Era. ASCAAD 2007, pp. 149-164.

3) Langer, E. J., 1989. Mindfulness, Reading, Mass., Perseus Books.

4) Muramatsu, S., Fujino, Yōzō, and Takafumi Noguchi. 2009. Stock management for sustainable urban regeneration. Vol. 4. Tokyo: Springer.

5) Oldenburg, Ray. 1991. The Great Good Place. New York: Marlowe \& Company. ISBN 978-1-56924-681-8.

6) Rahaman, Hafiz, 2012. A Framework for Digital Heritage Interpretation. Singapore: National University of Singapore.

7) Reffat, R. M., E. M. Nofal 2013, Effective Communication with Cultural Heritage Using Virtual Technologies in International Archives of the Photogrammetry, Remote Sensing and Spatial Information Sciences, Volume XL-5/W2, XXIV International CIPA Symposium, Strasbourg, France.

8) Roussou, M., 2002. Virtual Heritage: From the Research Lab to the Broad Public. Virtual Archaeology, pp. 93-100

9) Siltanen, S., 2012. Theory and applications of marker-based augmented reality. VTT Technical Research Centre of Finland.

10) UNESCO, 2011. "UNESCO Recommendation on the Historic Urban Landscape", accessed 18 July 2016, from http://whc.unesco.org/en/activities/638. 